\title{
IMPROVEMENT OF ADHESION, LINE DEFINITION, CON- TACT RESISTANCE AND SEMICONDUCTOR PROPERTIES BY SPUTTER-ETCHING
}

\author{
T. KALLFASS \\ Institut für Netzwerk- und Systemtheorie, Universität Stuttgart, Seidenstr. 36, \\ D-7000 Stuttgart, W. Germany
}

(Received June 12, 1978)

This paper was given at the International Conference on Thin and Thick Film Technology Augsburg 28-30 September 1977

\begin{abstract}
In an RF-sputtering unit, with suspended substrates mounted in lieu of a target, sputter-etching of the substrates and consecutive vapor deposition of $\mathrm{Au}$ is performed in order to achieve good adhesion of the Au-film without an adhesion layer. The method has been applied for surface-acoustic-wave filters on piezo ceramics and for noise measurements in Au-films on sapphire. The sputter-cleaning as described also reduces the disturbing contact resistance between the conductive $\mathrm{Cr}$-Au-layers and the previously sputtered Ta-film.

Considerable progress has also been made in the manufacture of thin-film transistors by photolithography, chemical etching, and sputter-etching instead of using evaporation masks.
\end{abstract}

\section{INTRODUCTION}

Gold layers vapor deposited onto glass or ceramic substrates or onto other films such as $\mathrm{Ta}_{2} \mathrm{O}_{5}$ or $\mathrm{Ta}$ usually require an adhesion layer of $\mathrm{Cr}, \mathrm{NiCr}$ or $\mathrm{Ti}$. In some applications we have to consider the contact resistance between the conductive films as well as the line definition whenever small structures are manufactured. Moreover, cleanness of surfaces is essential in the successful evaporating of semiconductive materials because of the sensitivity of semiconductors to all contaminations.

This paper describes how these problems can be solved by sputter-etching of the surfaces ${ }^{1}$ prior to the vapor deposition within the same vacuum system. The experiments can be divided into three groups:

a) Vapor deposition of $\mathrm{Au}$ on piezo ceramic for surface-acoustic-wave filters and deposition of $\mathrm{Au}$ layers on $\mathrm{Al}_{2} \mathrm{O}_{3}$-ceramic and sapphire, both without using adhesion layers.

b) Vapor deposition of $\mathrm{Cr}-(\mathrm{NiCr})$-Au-layers for the manufacture of integrated $\mathrm{R}-\mathrm{C}$-circuits with low contact resistances.

c) Vapor deposition of CdSe for thin-film transistors.

\section{DESCRIPTION OF THE EQUIPMENT AND OF THE SPUTTER-ETCH PROCESS}

In a modified RF-sputtering unit as shown in Figure 1 the substrates are attached to a suspended target which is water-cooled from the back. The substrate station formerly used below the shutter has been replaced by the vapor sources. The substrates are cleaned by sputter-etching using the closed shutter as anode and later on they are coated with material from the vapor sources after the shutter has been opened.

In detail the process is as follows. After initial pump down to $10^{-5}$ torr the RF-plasma is fired between the target and the closed shutter at an argon pressure of about $10^{-3}$ torr. The etching depth within the range of 10 Angstroms depends on the RF-power, the etching time and the surface material. The given

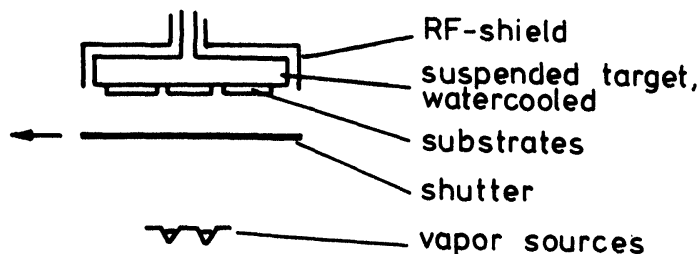

FIGURE 1 The sputtering unit. 
value for the depth is an estimated one. It was found to be too small to be measured because of the low sputter-rate of $\mathrm{Ta}_{2} \mathrm{O}_{5}$, the low power applied of only $0.5 \mathrm{~W} / \mathrm{cm}^{2}$ to $2.5 \mathrm{~W} / \mathrm{cm}^{2}$ and because of the short sputter time of only $4 \mathrm{~min}$ to $20 \mathrm{~min}$. After the sputter-cleaning, the plasma is shut off and the second pump down to $<10^{-5}$ torr is done in less than $1 / 2 \mathrm{~min}$. To reduce the time between cleaning and coating, pre-evaporation towards the lower side of the shutter is performed simultaneously to the second pump down. Finally the shutter is opened and the substrates are coated. The procedure, as described, is also applicable in large evaporation units with substrates mounted on rotating planetary wheels. For that the whole substrate holder has to be isolated and a suitable RF-power applied.

\section{VAPOR DEPOSITION OF Au WITHOUT ADHESION LAYER}

\subsection{Surface-acoustic-wave|Filter Applications}

The polished surface of the piezo-ceramic substrates was etched using a sputtering power of $800 \mathrm{~W}$ which corresponds to $2.5 \mathrm{~W} / \mathrm{cm}^{2}$ in the case of a 8 in target diameter. The sputtering time was $10 \mathrm{~min}$. The thickness of the evaporated Au was about $0.5 \mu \mathrm{m}$. The bonding pads were additionally electroplated up to $2 \mu \mathrm{m}$ to $5 \mu \mathrm{m}$.

In earlier experiments an adhesion layer of $\mathrm{Cr}$ was used. However, the Au-lines lost their accuracy and line definition during the time needed to remove the $\mathrm{Cr}$ totally from the piezo-ceramic because the etchant of the $\mathrm{Cr}$ attacked the ceramic. Therefore, the lack of an adhesion layer improves the line definition after etching of the $12 \mu \mathrm{m}$ wide fingers of the electroacoustic transducer of the filter. Due to the better line definition the reproducability and the performance of the filter is considerably improved.

\subsection{Gold Conductors}

$\mathrm{Au}$-layers were evaporated in order to measure current-noise effects in pure Au-films. These effects are so small that they can be observed only at high current densities and at temperatures above $900^{\circ} \mathrm{C}$. Therefore, a good adhesion of the $1 \mu \mathrm{m}$ thick Aulayer without any conductive under-layer was required. For substrate material mostly sapphire but also $\mathrm{Al}_{2} \mathrm{O}_{3}$-ceramic was used. Good adhesion was achieved by etching the sapphire surface with 2.5 $\mathrm{W} / \mathrm{cm}^{2}$ for $20 \mathrm{~min}$, whereas $\mathrm{Al}_{2} \mathrm{O}_{3}$-ceramic could be sufficiently cleaned in $10 \mathrm{~min}$.

\subsection{Experimental Results of the Tensile Strength Tests}

The two methods used for testing were a pull rod test and a wire pull test. The pull rod as shown in Figure 2 was attached normal to the surface of the substrate using a glue.

With the etching parameters given in 3.1. and 3.2. for polished piezo-ceramic, sapphire and $\mathrm{Al}_{2} \mathrm{O}_{3}$ substrates, but also for glass substrates the tests revealed adhesion forces $\geqslant 2 \mathrm{kp} / \mathrm{mm}^{2}$, where the area enlarged by the glue has been considered. At

TABLE I

Results of the wire pull tests

\begin{tabular}{|l|c|c|c|c|c|c|}
\hline substrate & wire diam & heat treatment & $\alpha=0$ & $\alpha=45^{\circ}$ & $\alpha=90^{\circ}$ & $\begin{array}{l}\text { fracture } \\
\text { occured in }\end{array}$ \\
\hline \multirow{2}{*}{\begin{tabular}{l}
\multirow{2}{*}{$\begin{array}{l}\mathrm{Al}_{2} \mathrm{O}_{3^{-}} \\
\text {ceramic }\end{array}$} \\
\cline { 2 - 8 }
\end{tabular}} & $200 \mathrm{um}$ & - & $300-350 \mathrm{p}$ & $200-250 \mathrm{p}$ & $50-60 \mathrm{p}$ & wire / film \\
\cline { 2 - 8 } & $200 \mathrm{um}$ & $30 \mathrm{~min} 950^{\circ} \mathrm{C}$ & $\sim 100 \mathrm{p}$ & & & film \\
\hline \multirow{3}{*}{ glass } & $50 \mathrm{um}$ & - & $\sim 35 \mathrm{pm}$ & $30-32 \mathrm{p}$ & & wire \\
\cline { 2 - 8 } & $50 \mathrm{um}$ & $2 \mathrm{hrs} 250^{\circ} \mathrm{C}$ & $\sim 20 \mathrm{p}$ & & & wire \\
\hline \multirow{3}{*}{ sapphire } & $200 \mathrm{um}$ & - & $350-400 \mathrm{p}$ & $250-300 \mathrm{p}$ & & wire $/$ film \\
\cline { 2 - 8 } & $200 \mathrm{um}$ & $30 \mathrm{~min} 950^{\circ} \mathrm{C}$ & $\sim 100 \mathrm{p}$ & & & film \\
\cline { 2 - 8 } & $50 \mathrm{um}$ & - & $\sim 40 \mathrm{p}$ & $\sim 35 \mathrm{p}$ & & wire \\
\hline
\end{tabular}




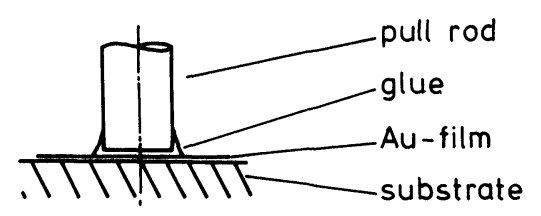

FIGURE 2 Pull rod test.

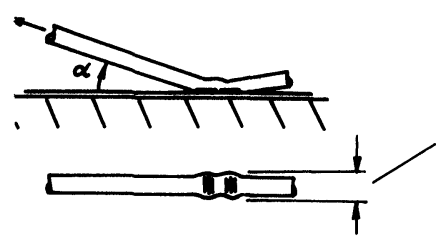

diameters of used $\mathrm{Au}$-wires: 50 um, 200um.

widening of the 50 um wire: $100-120 \mu \mathrm{m}$.

widening of the 200 um wire: was not noticeable.

FIGURE 3 Wire pull test.

larger forces these tests became unreliable because the glue partially broke.

The wire pull test, as shown in Figure 3, was performed with Au-wires bonded by thermocompression to the Au-film.

In Table I the measured values of the wire pull tests are listed. The adhesion forces decrease heavily when the angle $\alpha$ in Figure 3 is increased. Further heat treatment at $950^{\circ} \mathrm{C}$ strongly reduces the adhesion of the film. However, without heat treatment the wire itself or the wire/film interface was the weakest part.

\section{VAPOR DEPOSITION OF $\mathrm{Cr}-(\mathrm{NiCr})-\mathrm{Au}-$ LAYERS ON Ta-FILMS}

During the manufacturing process of integrated R's and C's using Ta-films doped with $\mathrm{N}_{2}$ and $\mathrm{O}_{2},{ }^{2-5}$ the $\mathrm{Ta}$ is coated with a thin oxide film when exposed to air. ${ }^{6}$ This is especially undesirable in the areas where conductors are to be attached as it may generate contact resistances in the range of $5 \mathrm{ohm}$ to $20 \mathrm{ohm}$. This value belongs to a Ta-resistor of about $100 \mu \mathrm{m}$ line width and conducting pads of $1 \mathrm{~mm}^{2}$ to $2 \mathrm{~mm}^{2}$. Additionally the adhesion usually decreases because of the contaminations originating from the production steps. By sputter-etching with a power of 0.5 $\mathrm{W} / \mathrm{cm}^{2}$ to $1.0 \mathrm{~W} / \mathrm{cm}^{2}$ during $2 \min$ to $4 \mathrm{~min}$ the contact resistance can be lowered down to $0.2 \mathrm{ohm}$ or less and the adhesion is increased again to the convenient values of $2 \mathrm{kp} / \mathrm{mm}^{2}$ to $5 \mathrm{kp} / \mathrm{mm}^{2}$. Using a larger power may damage the dielectrics on the substrate, which can be easily recognized by the decay of the break through voltages of the C's.

\section{VAPOR DEPOSITION OF CdSe FOR THIN FILM TRANSISTORS (TFT)}

The manufacture of TFT's is usually performed by vapor deposition of the layers on top of each other through masks in one vacuum sequence. ${ }^{7-10}$ In this technology contaminations can be kept off the semiconductor. However, problems occur at the fabrication, adjustment, and cleaning of the masks. It is therefore advantageous to evaporate the materials without masks in different vacuum steps and to apply photolithography and chemical etching if the cleanness of the surface can be still guaranteed. This is managed again by sputter-cleaning of the surfaces prior to the deposition of the semiconductor. Further details and characteristics of this transistor are reported by Kallfass and Lueder. ${ }^{11}$

\section{SUMMARY}

By means of some applications it is shown that adhesion forces, contact resistances, line definition and semiconductor properties can be improved by sputter-etching of the surfaces of substrates and films prior to vapour deposition of the next layers.

The investigations were made in a modified diode sputtering unit with suspended substrates mounted in place of the target, and with evaporation sources built in underneath a movable shutter. The same process is also applicable in large evaporation units.

\section{REFERENCES}

1. L. Holland, Vacuum Deposition of Thin Films (Chapman and Hall, London 1970).

2. E. Lueder, Bau Hybrider Mikroschaltungen (SpringerVerlag Berlin/Heidelberg, Germany, 1977).

3. H. Baeger, A single Ta-film for producing integrated temperature compensated R-C-networks, International Conference on Thin- and Thick-Film Technology, Sept. 1977, Augsburg, Germany.

4. H. W. Renz, Fabrication and performance of highly miniaturized distributed RC-active thin film circuits, International Conference on Thin- and Thick-Film Technology, Sept. 1977, Augsburg, Germany.

5. W. Worobey, Tantalum thin-film RC circuit technology for a universal active filter, IEEE Trans. P.H.P.-12, 4 (Dec. 76).

6. R. G. Duckworth, Conditions for the routine preparation of tantalum/aluminium films, Thin Solid Films, 26 (1975), 77-98.

7. P. K. Weimer, The Insulated-Gate Thin-Film Transistor, Physics of Thin Film, Vol. 2 (1964).

8. J. C. Anderson, Thin Film Transistors, Thin Solid Films, Vol. 36, 2, pp. 299 (1976). 
9. T. P. Brody, Fang Chen Luo, Zoltan P. Szepesi and D. H. Davies, A 6 × 6-in. 20 lpi electroluminescent display panel, IEEE Trans. on E1. Dev., Vol. ED-22, 9 (Sept. 75).

10. A. G. Fischer, Flat TV panels with polycrystalline layers, Microelectronics, Vol. 7, 4 pp. 5-15 (1976).
11. T. Kallfass, E. Lueder, High voltage thin film transistors with $\mathrm{Ta}_{2} \mathrm{O}_{5}$-gate-oxide and manufactured with photolithography, unpublished report. 

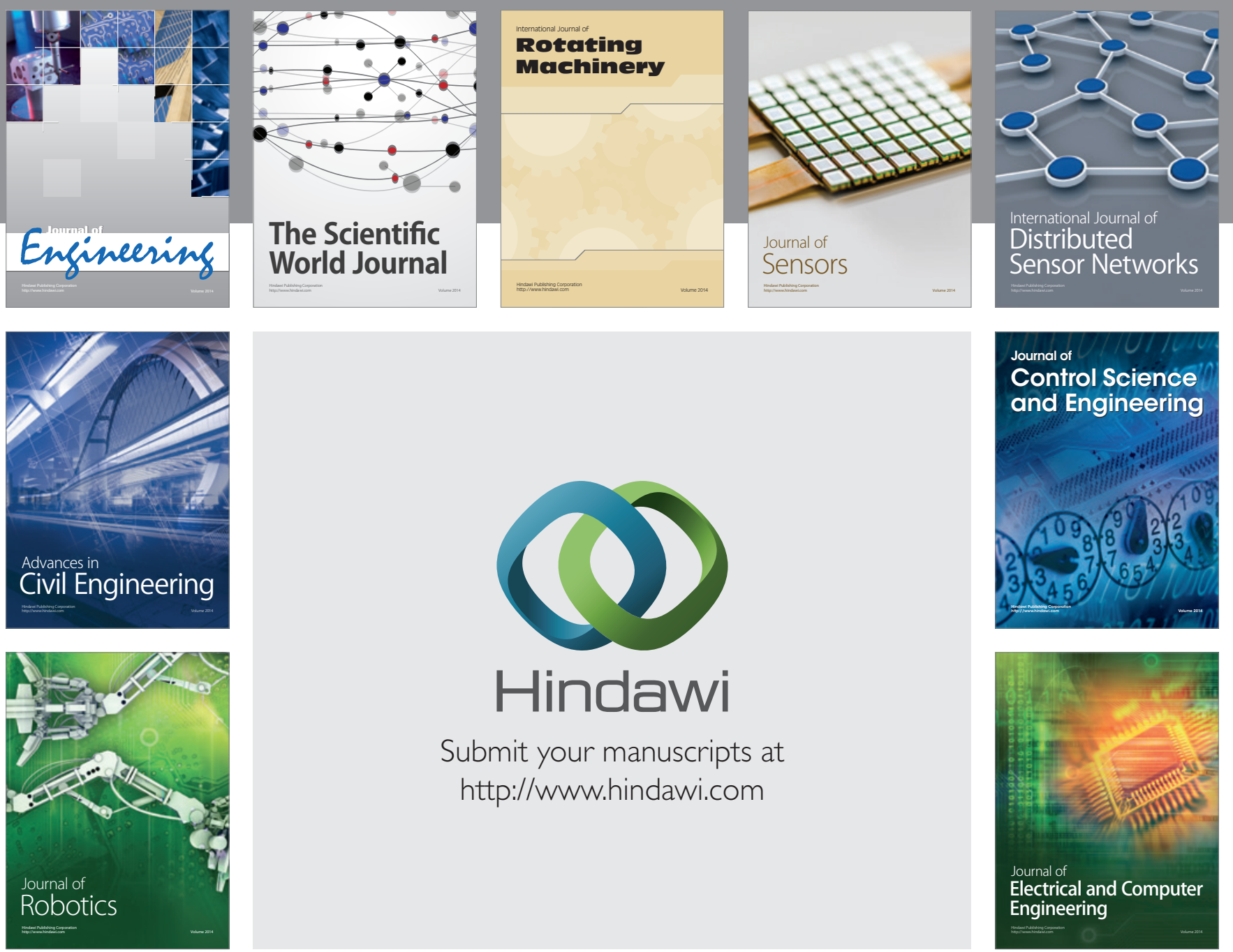

Submit your manuscripts at

http://www.hindawi.com
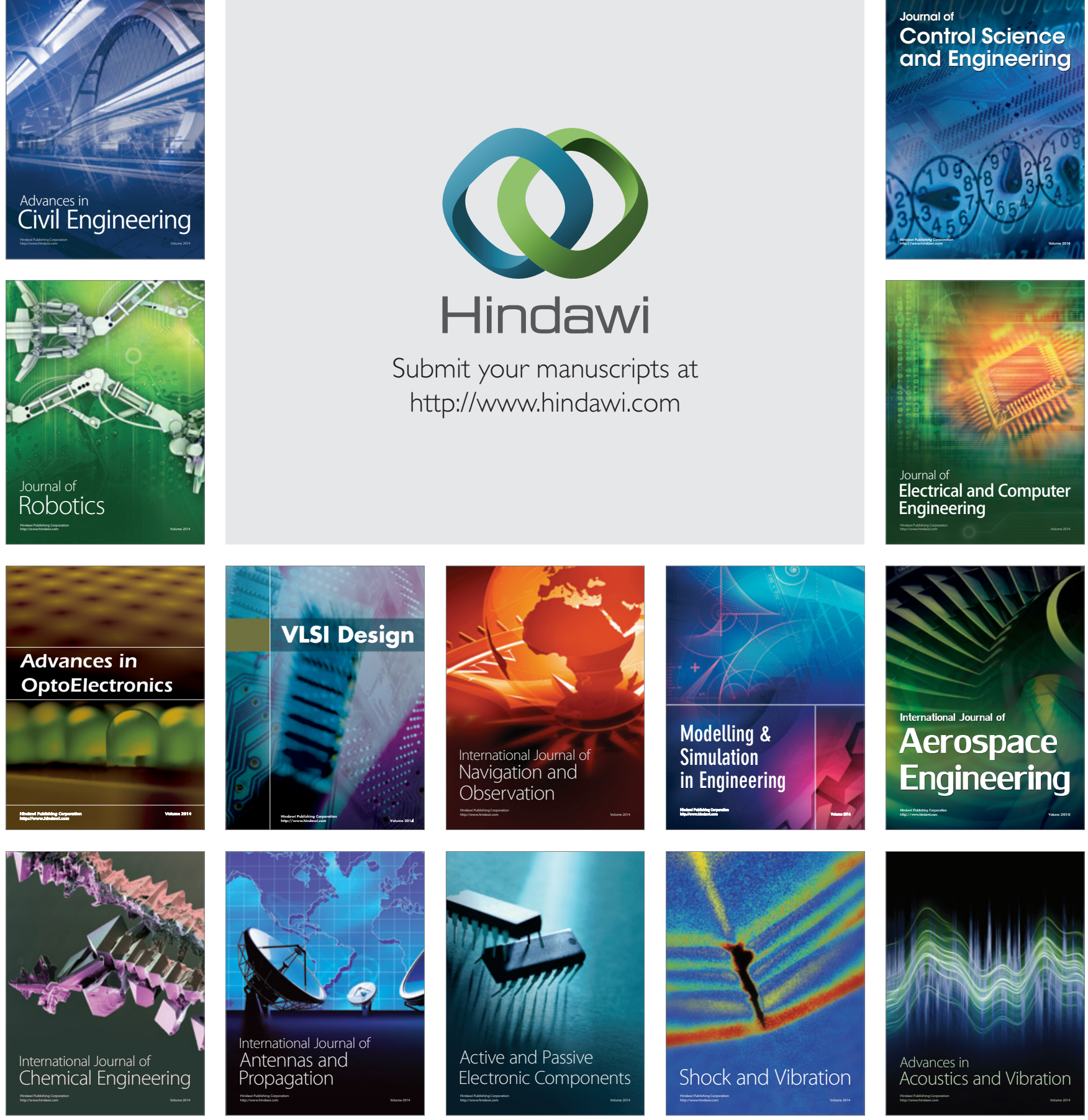